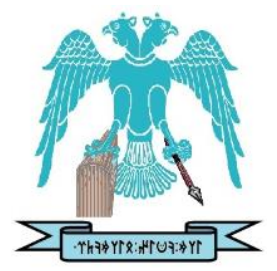

JOURNAL OF ENERGY SYSTEMS

$2021,5(2)$

\title{
Study of the effect of preparation parameters on thermal conductivity of metal oxide nanofluids using Taguchi method
}

\author{
Nikhil Shrikant Mane \\ BITS Pilani K K Birla Goa Campus, Department of Mechanical Engineering, Sancoale, Goa, India, \\ p20180023@goa.bits-pilani.ac.in \\ Vadiraj Hemadri ${ }^{(1 D}$ \\ BITS Pilani K K Birla Goa Campus, Department of Mechanical Engineering, Sancoale, Goa, India, \\ vadirajh@goa.bits-pilani.ac.in

$\begin{array}{rr}\text { Submitted: } & 25.02 .2021 \\ \text { Accepted: } & 24.05 .2021 \\ \text { Published: } & 30.06 .2021\end{array}$ \\ Abstract: The optimization of process parameters of the nanofluid preparation process for maximum \\ stability and high heat transfer is an active and important area of research. In this work, the effect \\ of the surfactant material, surfactant weight, and ultrasonication time are studied on distilled \\ water-based $\mathrm{CuO}, \mathrm{Fe}_{3} \mathrm{O}_{4}$, and $\mathrm{CuO}+\mathrm{Fe}_{3} \mathrm{O}_{4}$ nanofluids. Taguchi $\mathrm{L} 9$ orthogonal array was used for \\ the design of the experiment and 9 samples were prepared using this array. The effect of each \\ level of process parameter on the thermal conductivity is analyzed by calculating Signal to Noise \\ Ratio (SNR) and optimum levels of these parameters are identified. The crucial role of stability \\ in delivering high thermal conductivity nanofluids as predicted by SNR analysis is further \\ confirmed using Analysis of Variance (ANOVA).
}

Keywords: $\quad$ ANOVA, Nanofluids, Taguchi method, Thermal conductivity

Cite this paper as:

Mane, N.S., \& Hemadri V.A. Study of the effect of preparation parameters on thermal conductivity of metal oxide nanofluids using Taguchi method. Journal of Energy Systems 2021, 5(2), 149-164, DOI: $10.30521 /$ jes.872530

(c) 2021 Published by peer-reviewed open access scientific journal, JES at DergiPark (https://dergipark.org.tr/en/pub/jes)

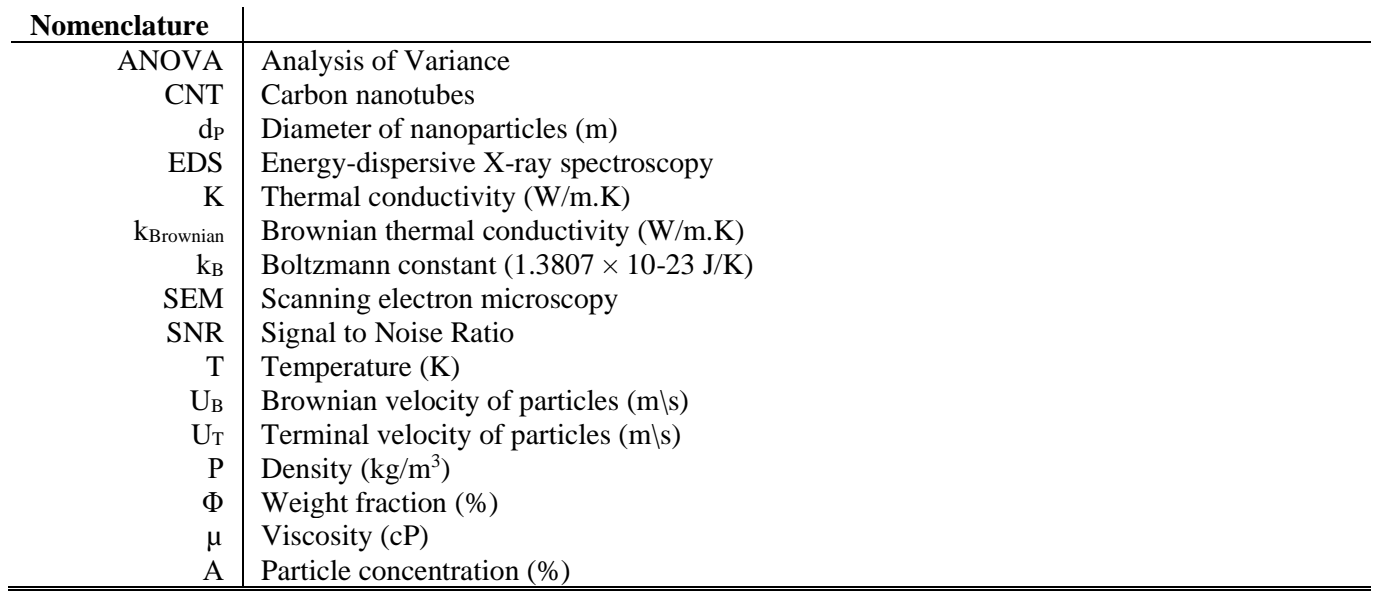




\section{INTRODUCTION}

Nanofluids offer many thermal, chemical, and practical advantages in medicine, engineering, and thermal applications. In heat transfer applications, users are generally interested in the thermal advantages offered by the nanofluids and focused on thermal conductivity, wettability, specific heat, and viscosity. Commonly used nanoparticles like CNT (carbon nanotubes), $\mathrm{Cu}, \mathrm{CuO}, \mathrm{Al}_{2} \mathrm{O}_{3}, \mathrm{Fe}_{3} \mathrm{O}_{4}$ delivers superior thermal conductivity compared to base fluid [1]. The high thermal conductivity and specific heat of the nanofluids make them an attractive option in heat pipes [2], heat exchangers [3] and IC engines [4,5]. Sajid et al. [6] have presented review on the applications of nanofluids in thermal applications like different types of heat exchanges and heat pipes. While using nanofluids in heat exchanging device different surfactants are needed to be used to increase the stability of nanofluids. Martin et al. [7] used water-based $\mathrm{Fe}+\mathrm{CuO}(50: 50)$ nanofluid (2 wt.\%) in heat pipe. They have used Triton X-100 (0.2 wt.\%) as a surfactant to stabilize nanofluid. Aydin et al. [8] used Triton X-100 and Sodium Dodecyl Benzene Sulfonate surfactants to stabilize Bauxite-water nanofluids and found 20.9\% enhancement in heat pipe efficiency with SDBS surfactant. Sozen et al. [9] used kaolin nanofluid in heat exchanger and found 9.3\% enhancement in heat transfer coefficient. Emine et al. [10] $\mathrm{CuO}+\mathrm{Al}_{2} \mathrm{O}_{3} /$ water hybrid nanofluid in a U-type tubular heat exchanger and found $12 \%$ enhancement in heat transfer coefficient at $1 \%$ concentration. These different nanofluids are effectively used in many applications as listed above, and these studies show the need of surfactants in nanofluids.

Many early studies ascribe the improvement in thermal conductivity to a reduction in thermal resistance because of well-dispersed solid particles in the nanofluid (effective medium theory) [11,12]. Later studies have shunned such a simplistic explanation and have characterized the heat transfer enhancement into static and Brownian thermal conductivity. An increase in the static thermal conductivity is explained by the mechanisms shown in Fig. 1.

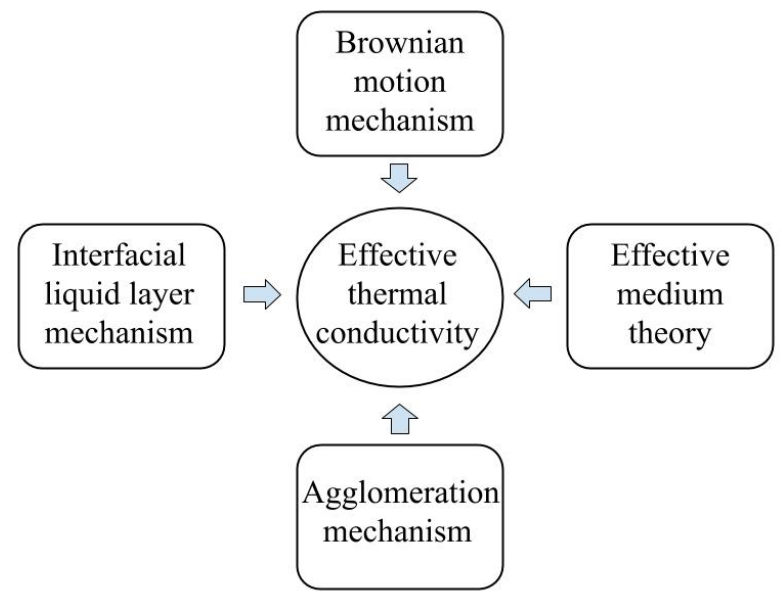

Figure 1. Mechanisms of thermal conductivity of nanofluids

The liquid layering of particle surface or interfacial liquid layer mechanism focuses on the formation of a very thin and organized layer of liquid molecules around the nanoparticles [13]. Henderson et al. [14] conducted a molecular dynamics study on the fluid and wall interface, based on which the authors suggested that there is a thin layer of fluid on the surface of the nanoparticle, the first layer has a thickness of less than half the diameter of the nanoparticle. This liquid layer has a higher thermal conductivity than the bulk because of the organized molecules around the solid particles. The thermal conductivity of the layer decreases along with the thickness of the layer away from the particle surface [15]. When these successive layers are formed around the particles in the nanofluid, a collective high thermal conductivity volume is formed in the nanofluid which increases the effective thermal conductivity. Other mechanisms associated with an enhancement in static thermal conductivity are the 
thermal diffusion of heat in close particles and clusters of nanoparticles, and high thermal conductivity paths created by the agglomerations of nanoparticles. In Brownian thermal conductivity, the Brownian motion of the nanoparticles in the liquid results in collisions. This solid-to-solid contact between the nanoparticles during collision allows heat transfer through conduction and a rise in overall thermal conductivity.

Stability is another important aspect of nanofluids. As the nanoparticles mixed in the base fluid should remain suspended in the fluid over a certain period, depending on the application, the study of the stability of nanofluid is inevitable. The stability of the nanofluid is generally characterized by zeta potential, hydrodynamic diameter, and visual observations. The nanoparticles in any nanofluid tend to agglomerate and settle down in the fluid over a period; this is called sedimentation of the nanofluids. Due to this, the nanofluids lose their advantage and show thermal properties similar to that of the base fluid [16]. Hence to improve the stability of nanofluids and to avoid sedimentation, surfactants are added to the nanofluid. The surfactant molecules consist of a hydrophobic tail and a hydrophilic head. When a surfactant is mixed in nanofluid, the hydrophobic tail attaches itself to the nanoparticle, while the hydrophilic head is in contact with water. This makes a cluster of nanoparticle and surfactant molecules that is hydrophilic [17]. The addition of a surfactant also increases the surface charge which leads to an increase in repulsive forces between the nanoparticles, which collectively results in the enhancement of the stability of the nanofluid [18]. Many studies have shown that the surfactant, in addition to increasing stability, also has an impact on the thermal properties of nanofluids. Xuan et al. [19] performed an experimental investigation to study the heat transferability of the $\mathrm{Cu}$-water nanofluid with SDBS surfactant. The findings of this study reveal that SDBS reduces the heat transfer coefficient in jet impingement heat transfer. The heat transfer further reduces with surfactant mass. The ultrasonication of nanoparticles is also commonly employed to enhance nanofluid stability [20,21]. This works by giving physical shocks to agglomerates formed by nanoparticles and physically breaks them into smaller particles.

As discussed earlier, the rise in thermal conductivity is the outcome of different mechanisms. Mugica et al. [22] have compiled different experimental studies of improvement in thermal conductivity and evaluated the hypothesis of thermal conductivity enhancement through Brownian motion. The authors point out the lack of repeatability in experimental results with the strength and weakness of each theory for thermal conductivity enhancement. The authors further found out that multiple physical variables contribute to thermal conductivity and the individual effect of these variables is not addressed. Hence in this paper, the evaluation of the process parameters (surfactant material, surfactant weight, ultrasonication time, and nanoparticle material) and their effect on the thermal conductivity of nanofluids is conducted using the Taguchi method. The Taguchi method is the design of experiments (DOE) tool employed to study stability and properties of nanofluids [23,24,25], and the number of studies using Taguchi methods in thermal applications are increasing as it offers much time saving compared to full factorial experimentation [26]. Taguchi method is used in this study to explore the effect of preparation parameters on the thermal conductivity. Taguchi methods provide quality results in less cost and time compared to other optimization techniques. Taguchi also allow obtaining quantitative results in few number of experiments. Hence in this work, the effect of process parameters and their levels on the thermal conductivity of distilled water-based $\mathrm{CuO}, \mathrm{Fe}_{3} \mathrm{O}_{4}$, and hybrid $\mathrm{CuO}+\mathrm{Fe}_{3} \mathrm{O}_{4}$ nanofluids is explored using the Taguchi method. This paper further studies the role of stability as a hidden contributor to thermal conductivity and explores the relationship between preparation parameters, stability, and thermal conductivity.

\section{METHODS AND MATERIALS}

To study the impact of the preparation parameters of nanofluid on its thermal conductivity, distilled water-based $\mathrm{CuO}, \mathrm{Fe}_{3} \mathrm{O}_{4}$, and hybrid $\mathrm{CuO}+\mathrm{Fe}_{3} \mathrm{O}_{4}$ nanofluids were selected. The weight of all three nanoparticles was maintained at $0.1 \%$ of the base fluid weight. To study the size and shape of 
nanoparticles scanning electron microscopy (SEM), and for purity energy-dispersive X-ray spectroscopy (EDS) techniques were also used. The images of $\mathrm{CuO}$ and $\mathrm{Fe}_{3} \mathrm{O}_{4}$ nanoparticles were obtained using a scanning electron microscope. It can be observed, in Fig. 2 that both nanoparticles have a size below $100 \mathrm{~nm}$ and spherical shape. EDS is a microanalysis technique that detects the presence of elements in the sample using X-rays in the electron microscope. Table 1 shows that the $\mathrm{CuO}$ and $\mathrm{Fe}_{3} \mathrm{O}_{4}$ nanoparticles are pure and does not contain any impurities or foreign element. The weight percentage and atomic percentage show the relative concentration of $\mathrm{Cu}, \mathrm{Fe}$, and $\mathrm{O}$ elements in the sample. For base fluid distilled water was used in which nanoparticles were mixed using stirring and ultrasonication.

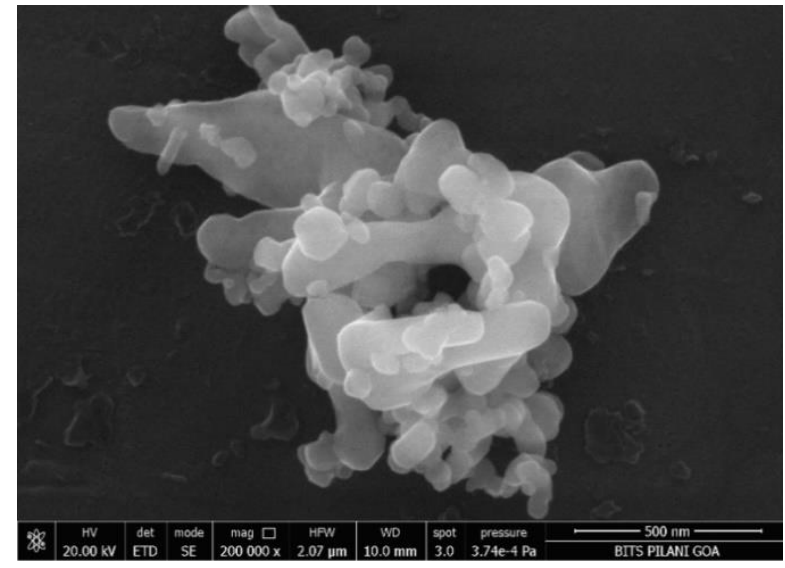

$\mathrm{CuO}$

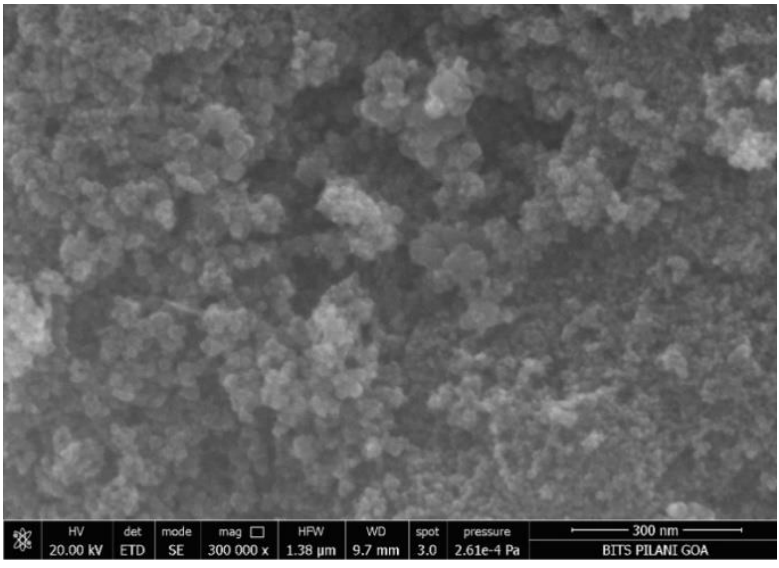

$\mathrm{Fe}_{3} \mathrm{O}_{4}$

Figure 2. SEM images of nanoparticles

Table 1. Composition of nanoparticles in EDS

\begin{tabular}{ccc}
\hline Nanoparticles & Weight $(\%)$ & Atomic (\%) \\
\hline $\mathrm{CuO}$ & $\mathrm{Cu}-95.9$ & $\mathrm{Cu}-85.5$ \\
& $\mathrm{O}-4.1$ & $\mathrm{O}-14.5$ \\
$\mathrm{Fe}_{3} \mathrm{O}_{4}$ & $\mathrm{Fe}-91.3$ & $\mathrm{Fe}-75$ \\
& $\mathrm{O}-8.7$ & $\mathrm{O}-25$ \\
\hline
\end{tabular}

\subsection{Taguchi method}

Taguchi analysis allows the extraction of maximum data from the minimum number of experiments. Whenever a large number of experiments are required to be performed to study a complex phenomenon, the Taguchi method is often utilized. It is a statistical design of experiment (DOE) tool that provides a sophisticated method for the design of experiments. In Taguchi analysis, experiments were designed using Orthogonal Arrays (OA). These orthogonal arrays give a specific arrangement of process parameters. This arrangement is such that it gives the minimum number of experiments to be performed while ensuring that all the necessary combinations of process parameters are covered in the design. The output of experiments cannot be interpreted directly as a common baseline to compare each level of process parameter is generally not available. Hence a signal to noise ratio (SNR) was calculated to interpret the results of these experiments [27]. The performance of each level of operating parameter was evaluated using SNR and a higher value of SNR shows a higher impact on the output of the experiment. In this work, surfactant material, surfactant weight, ultrasonication time, and nanoparticle material were selected as the process parameters and three levels of each process parameters are taken. The L9 orthogonal array was selected for the design of experiments based on parameters and their levels. As thermal conductivity is required to be highest as possible, it can be classified as 'Larger the better characteristics and in the 'Larger the better' quality characteristics the SNR was calculated using Equation 1;

$$
\mathrm{SNR}=10 * \log _{10} \frac{1}{\mathrm{n}}\left\{\left(\sum_{\mathrm{i}=1}^{\mathrm{n}} \frac{1}{\mathrm{y}_{\mathrm{i}}^{2}}\right)\right\}
$$

where, $y=$ observed characteristic, $n=$ number of observations of $y$. 


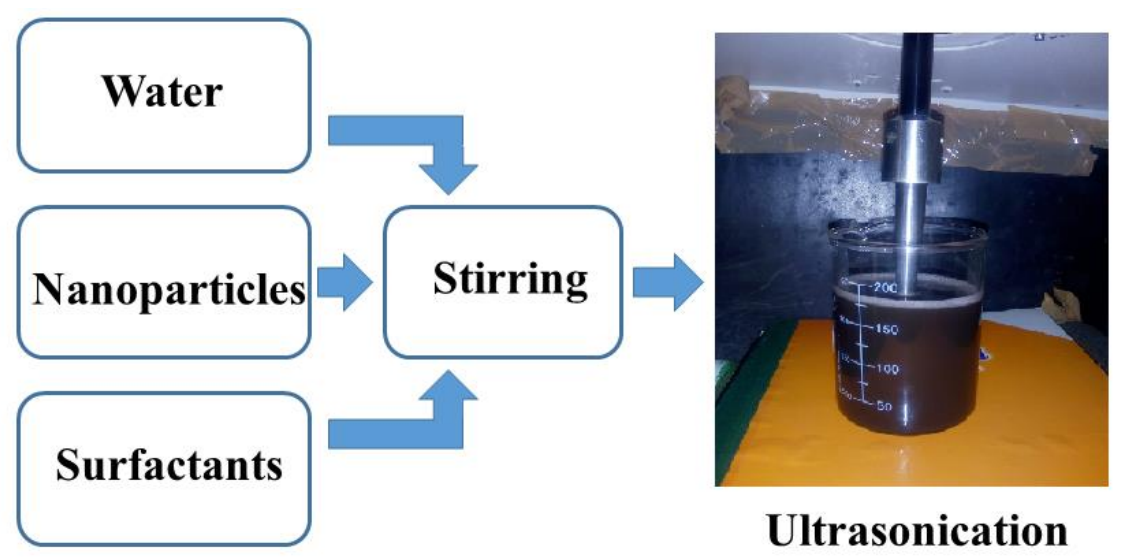

Figure 3. Preparation of nanofluid

Three surfactants; Citric Acid (CA), Sodium dodecyl sulfate (SDS), and Cetyl Trimethyl Ammonium Bromide (CTAB), three quantities of these surfactants; $0.05 \%, 0.1 \%$, and $0.5 \%$ of base fluid weight and three ultrasonication times; 15 minutes, 30 minutes, and 60 minutes, were selected as preparation parameters of the nanofluids as shown in Table 2. Most of these levels were selected based on the literature but to explore the effect of change in the process parameters the authors have taken the liberty in the selection of remaining levels. Based on L9 Taguchi Orthogonal Array (OA) 9 samples were prepared using these preparation parameters as shown in Table 3. The nanofluid was prepared by mixing distilled water with nanoparticles using a stirrer and ultrasonication as shown in Fig. 3. The ultrasonication frequency was maintained at $20 \mathrm{kHz}$ with 400 -Watt power.

Table 2. Process parameters with their levels

\begin{tabular}{ccccc}
\hline Process parameter & \multicolumn{5}{c}{ Level } & Unit \\
\hline Surfactant Material & $\mathrm{CTAB}$ & $\mathrm{CA}$ & $\mathrm{SDS}$ & - \\
Surfactant Weight & 0.05 & 0.1 & 0.5 & $\%$ of base fluid weight \\
Sonication Time & 15 & 30 & 60 & Minutes \\
Nanoparticle Material & $\mathrm{CuO}$ & $\mathrm{Fe}_{3} \mathrm{O}_{4}$ & $\mathrm{CuO}+\mathrm{Fe}_{3} \mathrm{O}_{4}$ & - \\
\hline
\end{tabular}

Table 3. Sample preparation based on L9 orthogonal array

\begin{tabular}{cl}
\hline Experiment (Specimen) & \multicolumn{1}{c}{ Composition } \\
\hline 1 & $\mathrm{CuO}+\mathrm{CTAB}(0.05 \%)+15$ minutes sonication \\
2 & $\mathrm{Fe}_{3} \mathrm{O}_{4}+\mathrm{CTAB}(0.5 \%)+30$ minutes sonication \\
3 & $\left(\mathrm{CuO}+\mathrm{Fe}_{3} \mathrm{O}_{4}\right)+\mathrm{CTAB}(0.1 \%)+60$ minutes sonication \\
4 & $\left(\mathrm{CuO}+\mathrm{Fe}_{3} \mathrm{O}_{4}\right)+\mathrm{CA}(0.05 \%)+30$ minutes sonication \\
5 & $\mathrm{CuO}+\mathrm{CA}(0.1 \%)+60$ minutes sonication \\
6 & $\mathrm{Fe}_{3} \mathrm{O}_{4}+\mathrm{CA}(0.5 \%)+15$ minutes sonication \\
7 & $\mathrm{Fe}_{3} \mathrm{O}_{4}+\mathrm{SDS}(0.05 \%)+60$ minutes sonication \\
8 & $\left(\mathrm{CuO}+\mathrm{Fe}_{3} \mathrm{O}_{4}\right)+\mathrm{SDS}(0.1 \%)+15$ minutes sonication \\
9 & $\mathrm{CuO}+\mathrm{SDS}(0.5 \%)+30$ minutes sonication \\
\hline
\end{tabular}

\section{STABILITY OF NANOFLUIDS}

Visual observations and turbidity measurements were used to study the stability of nanofluids. Turbidity was measured over a period using a Turbidity meter (Make-Lutron, Model- TU-2016). The turbidity of each sample was recorded every $60^{\text {th }}$ minute from the preparation till 360 minutes. Turbidity measurement provides the amount of light scattered by the nanofluids samples due to the presence of 
nanoparticles in the sample. The monitoring of turbidity over a period offers a quantitative observation of the state of nanoparticles present in the sample.

It can be observed from Table 4 that samples $1,2,3,7,8$, and 9 are stable for a longer period than samples 4, 5, and 6. Visual observations showed that sample 4, 5, and 6 shows rapid settlement and visible agglomeration within a few hours. The other samples were stable over a longer period; sample 2 showed the initiation of the settlement of the particles after 12 hours, and samples $1,3,7,8$, and 9 showed settlement initiation after 24 hours. Once the settlement of particles was initiated, these samples still hold a small number of particles till 15 days after preparation. It can be observed from Fig. 4 that after 15 days most of the particles in the samples are settled. But still, samples 1, 2, 3, 7, 8, and 9 had a higher density than samples 4,5 , and 6 . Though, visual observation is the simplest method of sedimentation monitoring, due to different materials of nanoparticles the opacity of the sample varies. The comparison between dark-colored nanofluids $\left(\mathrm{CuO}, \mathrm{Fe}_{3} \mathrm{O}_{4}, \mathrm{CNT}\right)$ and bright white-colored nanofluids $\left(\mathrm{TiO}_{2}, \mathrm{Al}_{2} \mathrm{O}_{3}\right)$ becomes very difficult. Hence more reliable methods of stability monitoring can be employed for long-term monitoring of nanofluid stability.

Table 4. Stability of Nanofluid specimen

\begin{tabular}{|c|c|c|c|}
\hline \multirow[b]{2}{*}{$\begin{array}{l}\text { Sample } \\
\text { No. }\end{array}$} & \multicolumn{2}{|c|}{ Turbidity } & \multirow[b]{2}{*}{ Visual Observations } \\
\hline & $\begin{array}{l}0 \text { minutes } \\
\text { after } \\
\text { preparation }\end{array}$ & $\begin{array}{l}360 \text { minutes } \\
\text { after } \\
\text { preparation }\end{array}$ & \\
\hline 1 & 64 & 801 & Stable for more than 24 hours \\
\hline 2 & 241 & 343 & Stable for more than 12 hours \\
\hline 3 & 38 & 599 & Stable for more than 24 hours \\
\hline 4 & 71 & 26 & $\begin{array}{l}\text { Sedimentation initiates within the } 2 \text { hours after preparation } \\
\text { Complete settling of nanoparticles takes place in } 9 \text { hours }\end{array}$ \\
\hline 5 & 97 & 50 & $\begin{array}{l}\text { Sedimentation initiates within } 45 \text { minutes after preparation } \\
\text { Complete settling of nanoparticles takes place in } 6 \text { hours }\end{array}$ \\
\hline 6 & 134 & $71 \mathrm{f}$ & $\begin{array}{l}\text { Sedimentation initiates within the } 2 \text { hours after preparation } \\
\text { Complete settling of nanoparticles takes place in } 9 \text { hours }\end{array}$ \\
\hline 7 & 204 & 213 & Stable for more than 24 hours \\
\hline 8 & 46.89 & 768 & Stable for more than 24 hours \\
\hline 9 & 37.55 & 781 & Stable for more than 24 hours \\
\hline
\end{tabular}

The turbidity measurement is an optical measurement process in which light is passed through the nanofluid sample and scattered light from nanoparticles is measured to calculate the turbidity. It can be observed in Fig. 5 that in samples 1, 2, 3, 7, 8, and 9 the turbidity of the nanofluid was increased considerably over 360 minutes. The presence of more nanoparticles with high mobility in the nanofluid reduces the amount of light scattered, hence in the initial period of nanofluid life the turbidity was lower. As time increases, the agglomeration of the nanoparticles takes place which increases the size of nanoparticle clusters and reduces their mobility. The increased size of the nanoparticle clusters causes higher light scattering in the fluid [20]. Due to this, the turbidity of samples 1,2,3, 7, 8, and 9 increased as a result of increased particle cluster size. In samples 4,5 , and 6 , the turbidity was observed to be decreased in 360 minutes after preparation. In these samples, the rapid agglomeration and sedimentation of the particles took place. Due to very high agglomeration, the nanoparticle clusters start settling down in the fluid, and nanoparticles in the fluid decrease. This low number of particles reduces the amount of light scattered and much of the incident light transmitted through the solution which reduces the turbidity. From visual observations and turbidity monitoring, it can be concluded that the surfactants CTAB and SDS provide more stable nanofluids than CA. 


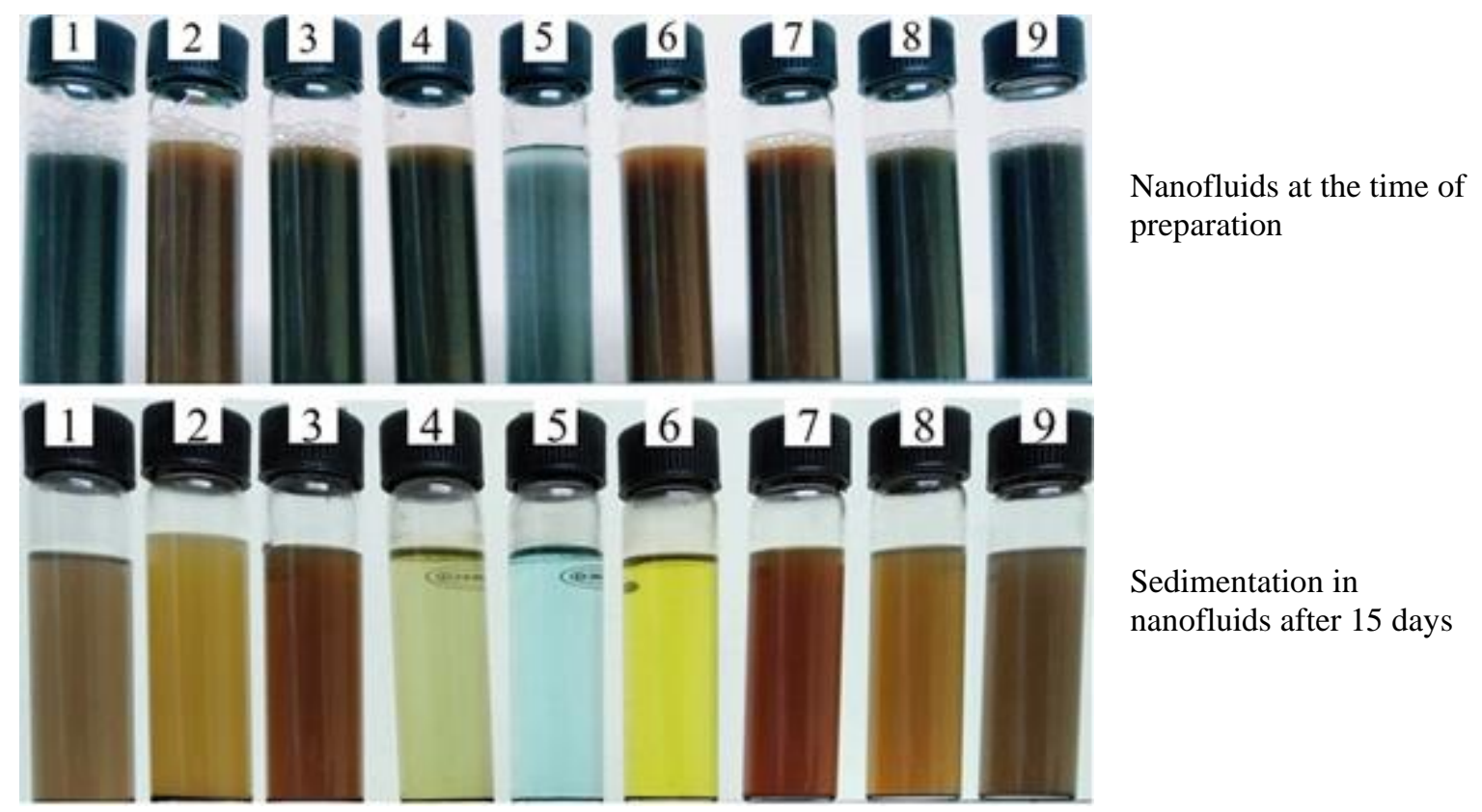

Figure 4. Photograph of nanofluid samples

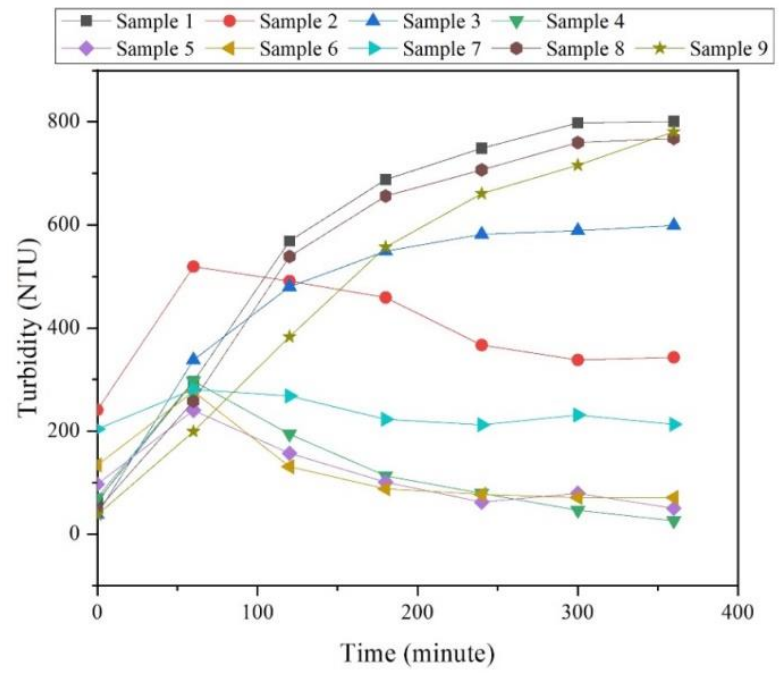

Figure 5. Turbidity behavior of nanofluid samples

Sample 2 and sample 7 were observed to be stable in visual observation and their turbidity was lower than other stable samples at the end of 360 minutes. The refractive index of fluid and particles affect the amount of light scattered. In this study, three different materials were used for nanofluid preparation and due to different refractive indices, samples with different materials show different turbidity. Due to different refractive indices of the particles, the $\mathrm{Fe}_{3} \mathrm{O}_{4}$-water nanofluids showed different turbidity behavior compared to $\mathrm{CuO}$-water and $\mathrm{CuO}+\mathrm{Fe}_{3} \mathrm{O}_{4}$-water nanofluids.

Along with turbidity, the Brownian velocity and terminal settling velocity were also calculated to study the stability of nanofluids. Allen et al. [28] presented an Equation 2 to determine the Brownian velocity;

$$
U_{B}=\frac{2 k_{B} T}{\pi \mu_{n f} d_{p}^{2}}
$$

And the terminal velocity of the particle for settling was determined using Equation 3, 


$$
U_{T}=\frac{g d_{p}^{2}\left(\rho_{n p}-\rho_{n f}\right)}{18 \mu_{n f}}
$$

At a high Brownian velocity, the nanoparticles travel at a high speed in the fluid which reduces the possibility of agglomeration. The intermolecular attractive forces are weak when particles are moving at a high velocity. The terminal settling velocity is the velocity at which a particle starts to settle in the fluid due to gravity. The particle has the gravitational force acting on it but due to high Brownian motion, the particle can overcome it. Initially, a particle will have a certain Brownian velocity but as the aging of nanofluid takes place due to agglomeration, the increased particle size will reduce the Brownian velocity. When the Brownian velocity reaches terminal settling velocity the particle is no longer able to overcome the gravitational force and settles down in the fluid. Hence to achieve high stability, the nanoparticles should have higher Brownian motion than the terminal settling velocity. A higher ratio of Brownian velocity and terminal settling velocity ensures higher stability of nanofluids [29]. Both Brownian and terminal settling velocity of the particles was strongly influenced by the particle size, as low size particles have higher Brownian motion and lower terminal settling velocity [30].

In this work, the viscosity of nanofluid samples was measured at $25^{\circ} \mathrm{C}$ using Brookfield DV2T viscometer (accuracy $= \pm 1 \%$ ). And the density of the nanofluid was calculated using

$$
\rho_{n f}=\Phi \rho_{n p}+(1-\Phi) \rho_{b f}
$$

The particle sizes of the nanofluids were measured using dynamic light scattering analysis. Using all these properties, the Brownian velocity and terminal settling velocity were calculated and tabulated in Table 5 .

Table 5. Brownian and terminal settling velocity of nanofluid samples.

\begin{tabular}{cccccccccc}
\hline & Sample 1 & Sample 2 & Sample 3 & Sample 4 & Sample 5 & Sample 6 & Sample 7 & Sample 8 & Sample 9 \\
\hline Viscosity $(\mathrm{cP})$ & 0.98 & 0.97 & 1.01 & 0.90 & 1.04 & 0.94 & 0.93 & 0.93 & 0.94 \\
$\mathrm{U}_{\mathrm{B}} \times 10^{5}$ & 4.806 & 2.425 & 2.756 & 0.208 & 0.013 & 0.151 & 13.985 & 3.469 & 5.236 \\
$\mathrm{U}_{\mathrm{T} \times 10^{8}}$ & 16.430 & 26.460 & 24.958 & 403.770 & 5151.776 & 450.478 & 4.99 & 22.688 & 16.230 \\
$\mathbf{U}_{\mathbf{B}}$ & 292.99 & 91.83 & 113.85 & 0.517 & 0.0026 & 0.336 & 2798.6 & 152.91 & 322.55 \\
$\mathbf{U}_{\mathbf{T}}$ & & & & & & & & & \\
\hline
\end{tabular}

The samples showed different viscosity values even though they are at the same concentration. This difference in viscosity was the result of the use of different surfactants and agglomeration sizes of the nanoparticles. It can be observed that samples 1, 2, 3, 7, 8, and 9 have considerably higher Brownian motion than samples 4,5 , and 6 . There was a faster rate of agglomeration in the nanofluid samples prepared using the TX-100 surfactant. Sample 7 showed the highest velocity ratio which shows that it is more stable than the rest of the nanofluid samples included in this study. It was also observed that samples 4,5 , and 6 have a velocity ratio lower than unity, indicating that the particles in these samples are at a lower Brownian velocity compared to their terminal velocity. This explains the higher sedimentation and low life of these nanofluid samples.

\section{EXPERIMENTAL SETUP}

Fig. 6 shows the experimental setup where a $25^{\circ} \mathrm{C}$ temperature was maintained using a jacketed beaker and constant temperature bath. The specifications of apparatus/instruments used in the experimental setup are provided in Table 6 . 


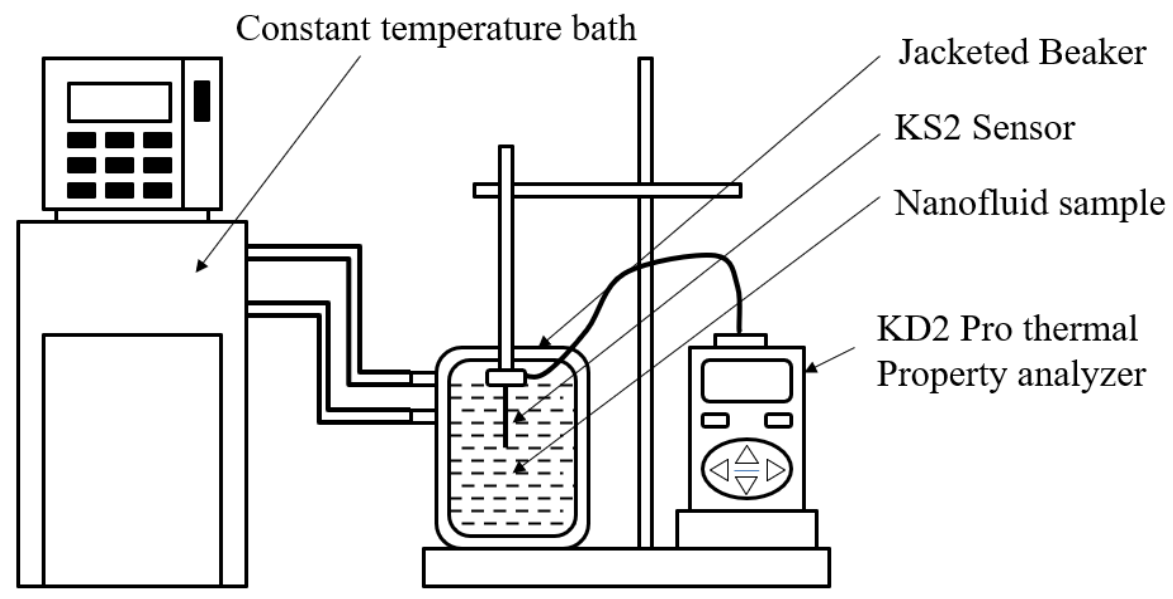

Figure 6. Experimental setup for measurement of thermal conductivity

Table 6. Specifications of components of the experimental setup

\begin{tabular}{lccc}
\hline \multicolumn{1}{c}{ Components } & Variant/Model & Make & Accuracy \\
\hline Thermal Property Analyzer & KD2 Pro with KS-1 Sensor & Decagon Devices & $0.005 \mathrm{~W} / \mathrm{m}^{20} \mathrm{C}$ \\
Constant Temperature Bath & F25 & Julabo & $0.01^{\circ} \mathrm{C}$ \\
Jacketed beaker & - & Optech & - \\
\hline
\end{tabular}

For thermal conductivity measurement, a thermal property analyzer KD2 pro was used. To increase the accuracy of measurement, 10 readings were taken for each sample while 15 minutes of the time interval is maintained between two readings. To study the accuracy of experimental measurements, the thermal conductivity of distilled water was recorded at $25^{\circ} \mathrm{C}, 30^{\circ} \mathrm{C}, 35^{\circ} \mathrm{C}$, and $40^{\circ} \mathrm{C}$. These measurements were then compared with standard NIST data [31] (refer to Fig. 7). A maximum error of $0.5 \%$ was observed at $35^{\circ} \mathrm{C}$.

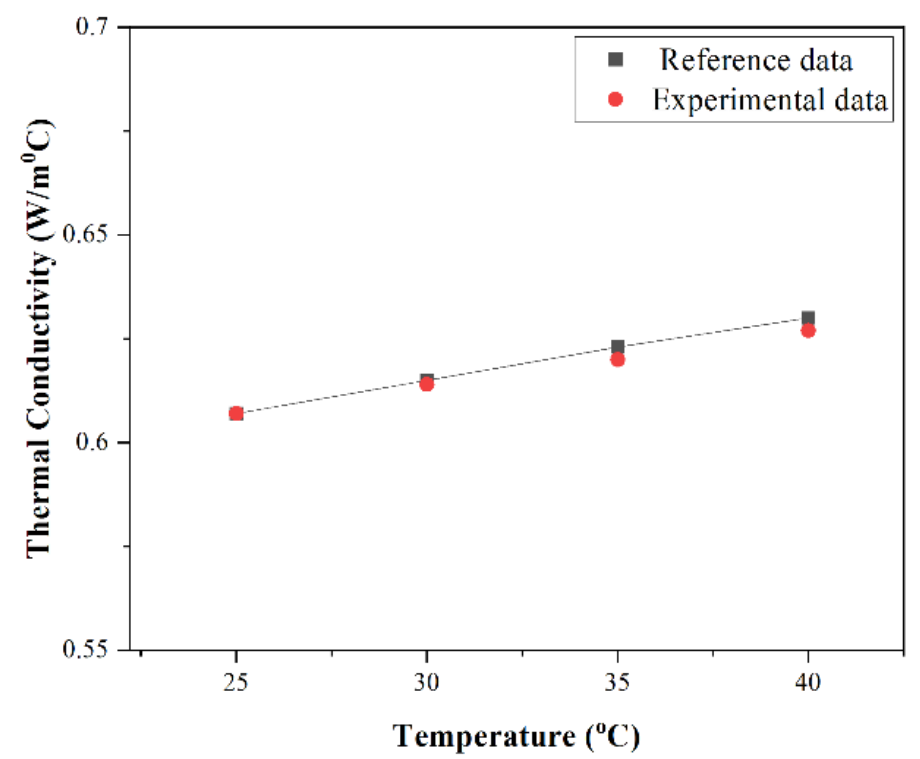

Figure 7. Validation of measured thermal conductivity with NIST data

In this study, Uncertainty analysis was conducted to validate the obtained results. The uncertainties in the results are emerged from temperature of samples and thermal conductivity measurement. In order to determine the uncertainties in the experimental measurement it is assumed that the measuring devices 
are showing their maximum errors. To find uncertainty in thermal conductivity measurement, the methodology of Holman et al. [32] was followed,

$$
\mathrm{U}_{\mathrm{F}}=\left[\left(\frac{\delta O}{\delta X_{1}} u_{1}\right)^{2}+\left(\frac{\delta O}{\delta X_{2}} u_{2}\right)^{2}+\cdots \ldots \ldots+\left(\frac{\delta O}{\delta X_{n}} u_{n}\right)^{2}\right]^{\frac{1}{2}}
$$

This Equation (5) provides uncertainty $\left(\mathrm{U}_{\mathrm{F}}\right)$ in final value of the measurement calculated using uncertainties $\left(\mathrm{u}_{1}, \mathrm{u}_{2} \ldots \ldots \mathrm{u}_{\mathrm{n}}\right)$ of independent variable $\left(\mathrm{X}_{1}, \mathrm{X}_{2} \ldots \ldots \ldots \mathrm{X}_{\mathrm{n}}\right)$. Because of high accuracy of the thermal property analyzer and constant temperature bath, the calculated total uncertainty in the experimental measurement is $0.01 \%$ which in acceptable limit.

\section{RESULTS AND DISCUSSION}

\subsection{Signal to Noise ratio (SNR)}

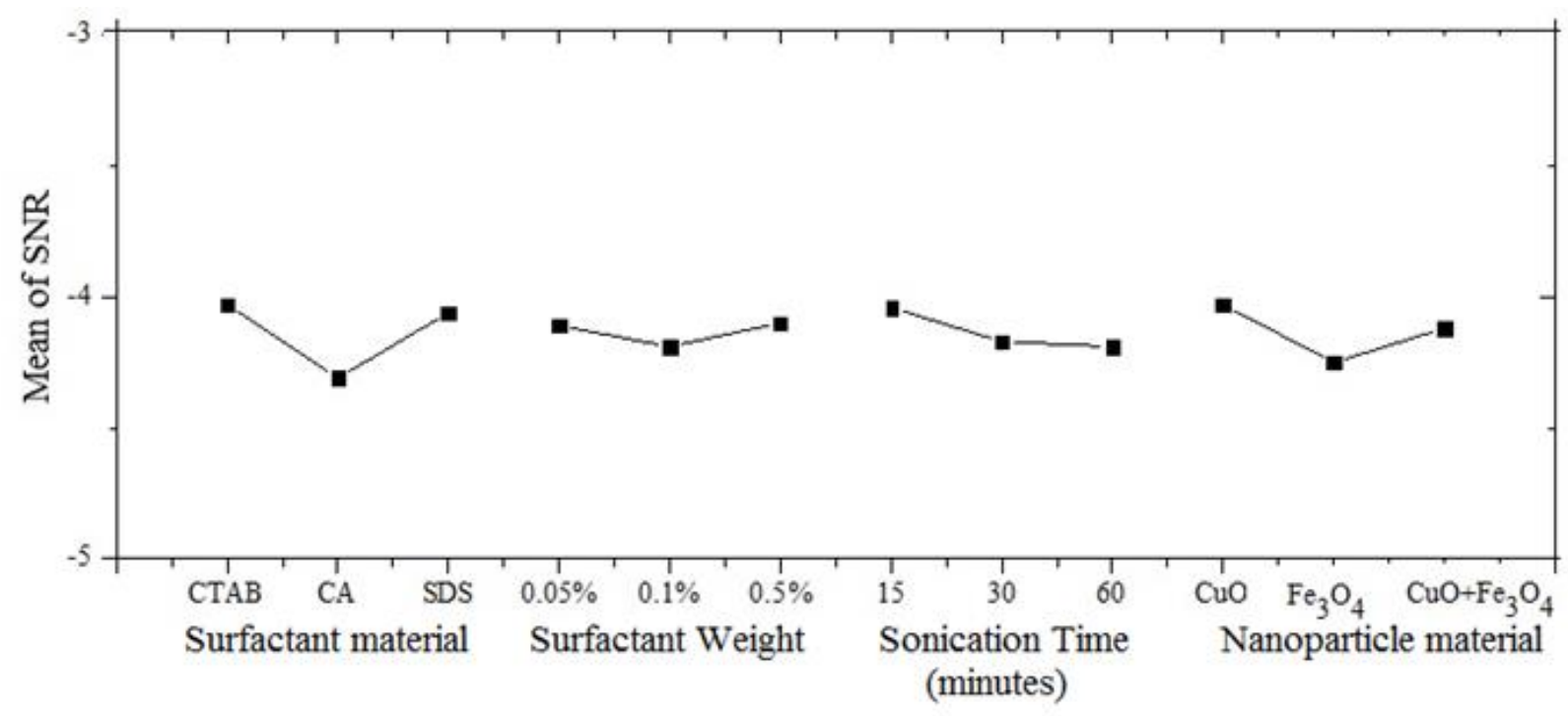

Figure 8. Effect of process parameters on thermal conductivity

After measurement of the thermal conductivity of the samples, the Taguchi analysis was conducted, and SNR was calculated. Fig. 8 shows the calculated SNR for each process parameter. Fig. 8 shows that CA shows the lowest SNR for thermal conductivity, and nanofluid samples with CTAB as surfactant shows the highest SNR. The average value of thermal conductivity for nanofluids with CTAB and SDS is $3.28 \%$ and $2.9 \%$ higher than nanofluids with $\mathrm{CA}$ as the surfactant. This indicates that for high thermal conductivity CTAB is the best performing surfactant material. The nanofluid samples with CA show the lowest thermal conductivity and show merely $0.5 \%$ enhancement than thermal conductivity of distilled water. The nanofluid samples prepared using CA are also the least stable nanofluids and hence the lower thermal conductivity is the result of agglomeration and rapid settlement of nanoparticles. The increased size of the particles due to agglomeration reduces the Brownian motion of the nanoparticles. Also, the settlement of the nanoparticles leads to fewer particles in the nanofluid. This collectively resulted in low thermal conductivity of nanofluid with CA surfactant.

The effect of surfactant quantity on the thermal conductivity can be observed from the mean value of SNR in Fig. 8. It is observed that the SNR decreases when surfactant quantity is increased from $0.05 \%$ to $0.1 \%$ and it further increases by $0.5 \%$. The chemistry of the nanofluids is much more complex, the mere quantity of surfactant is not important in the nanofluid composition as different surfactants have different optimum concentrations for lower particle size and high particle mobility. This optimum concentration of surfactant is dependent on the surfactant material, nanoparticle material, and the base 
fluid. Hence, here a direct relation between surfactant quantity and thermal conductivity cannot be established, but within the constraints of this work the $0.5 \%$ concentration of the surfactants provides higher thermal conductivity.

Fig. 8 also shows that with an increase in ultrasonication time, the mean value of SNR decreases. This shows that at higher ultrasonication time, the thermal conductivity of the nanofluid decreases. Though the thermal conductivity should be enhanced with ultrasonication time, the worst results obtained by other process parameters like surfactant material and nanoparticle material has overshadowed the better performance of the higher ultrasonication time. This is the limitation of the Taguchi method, where the interaction of the different process parameters is not taken into consideration which decreases the quality of the results. It can be observed that the thermal conductivity of nanofluid is a direct product of the thermal conductivity of the nanoparticle material in accordance with effective medium theory. Fig. 8 also shows that the $\mathrm{CuO}$-water nanofluid has the highest $\mathrm{SNR}$ for thermal conductivity as $\mathrm{CuO}$ material has higher thermal conductivity than $\mathrm{Fe}_{3} \mathrm{O}_{4}$ and a mixture of $\mathrm{CuO}+\mathrm{Fe}_{3} \mathrm{O}_{4}$ material. The $\mathrm{CuO}$-water nanofluids have the highest thermal conductivity and $\mathrm{Fe}_{3} \mathrm{O}_{4}$-water nanofluids show the lowest thermal conductivity in this study. It is found that the average value of the thermal conductivity of $\mathrm{CuO}$-water, $\mathrm{Fe}_{3} \mathrm{O}_{4}$-water, and $\mathrm{CuO}+\mathrm{Fe}_{3} \mathrm{O}_{4}$-water is increased compared to the base fluid by $3.65 \%, 1.19 \%$, and $2.62 \%$, respectively.

\subsection{Analysis of variance (ANOVA)}

ANOVA is a statistical tool used for the interpretation of data obtained in experimentations. It provides the significance of each process parameter in the output of the experiment. Using the Taguchi method, the effect of each level of process parameters can be compared amongst themselves, whereas ANOVA determines the contribution of each process parameter in the output [33]. Predicted residual error of sum of squares found during ANOVA calculation is $0.16 \%$. Using ANOVA, the best performing levels of each parameter and their effect on the thermal conductivity of the nanofluid are obtained and listed in Table 7.

Table 7. Optimum Conditions.

\begin{tabular}{lll}
\hline \multicolumn{1}{c}{ Process Parameter } & Optimum Level & Effect on Thermal Conductivity \\
\hline Surfactant Material & CTAB & Dominant \\
Surfactant Weight $(\%)$ & 0.5 & Significant \\
Sonication Time (minutes) & 15 & Dominant \\
Nanoparticle Material & $\mathrm{CuO}$ & Dominant \\
\hline
\end{tabular}

ANOVA was conducted to investigate the individual contribution of surfactant material $(52.5 \%)$, surfactant weight $(5.8 \%)$, sonication time $(15.1 \%)$, and nanoparticle material $(26.6 \%)$ on the thermal conductivity. As shown in Fig. 9, that surfactant material has a maximum impact on the thermal conductivity which is almost twice more than the material of nanoparticles. Even though it is controversial to claim that the surfactant material has a higher contribution to the thermal conductivity than nanoparticle material; this can be explained through stability. Considering the complex behavior of nanofluids, it is not correct to conclude that the surfactant material, surfactant weight, and ultrasonication time of nanofluid preparation have a direct impact on the thermal conductivity of the nanofluid. The surfactant material, surfactant weight, and ultrasonication time have a more direct impact on the stability of the nanofluids and hence the dominant effect of these factors on the thermal conductivity noticed using ANOVA is a result of the stability of nanofluids. 


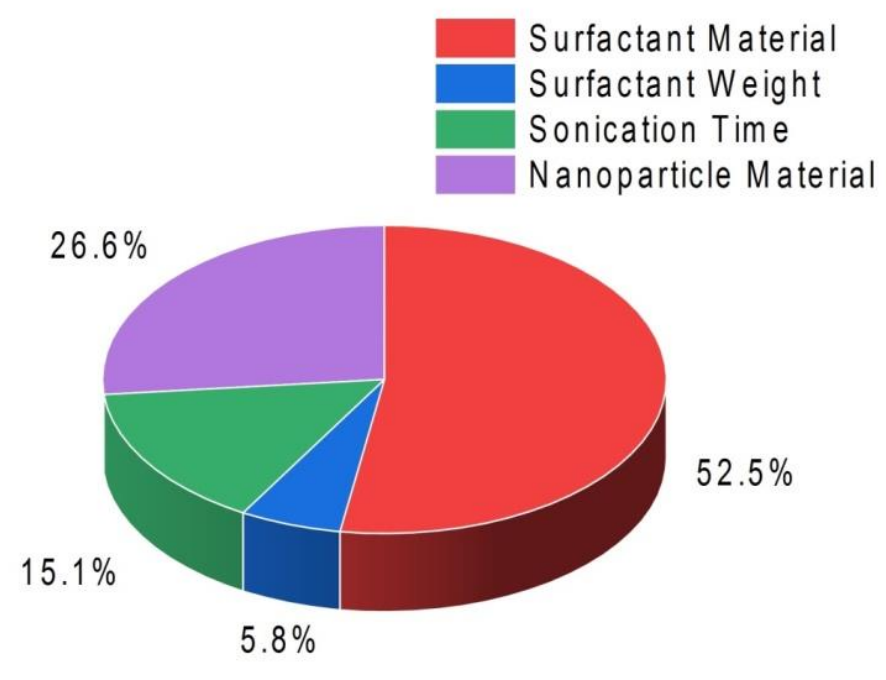

Figure 9. Effect of process parameters on thermal conductivity

The optimum levels of the surfactant material, surfactant weight, and ultrasonication time provide stable nanofluids and thus provide a higher thermal conductivity of the nanofluid compared to a less stable sample of the same nanofluid material. The visual observations of the nanofluid stability also suggest that the stable nanofluid provides considerably higher thermal conductivity than less stable nanofluids of the same material. The surfactants prevent agglomeration and hence surfactants with optimum concentration can enhance the thermal conductivity of the nanofluid [34,35]. From all these observations it can be concluded that the stability of nanofluid has a high impact on thermal conductivity. As the surfactant material, surfactant weight and ultrasonication time play a direct role in the stability of the nanofluid, these parameters can be considered as stability parameters. From Fig. 10 it can be observed that the stability is more influential on the thermal conductivity of the nanofluid than the material of the nanofluid.

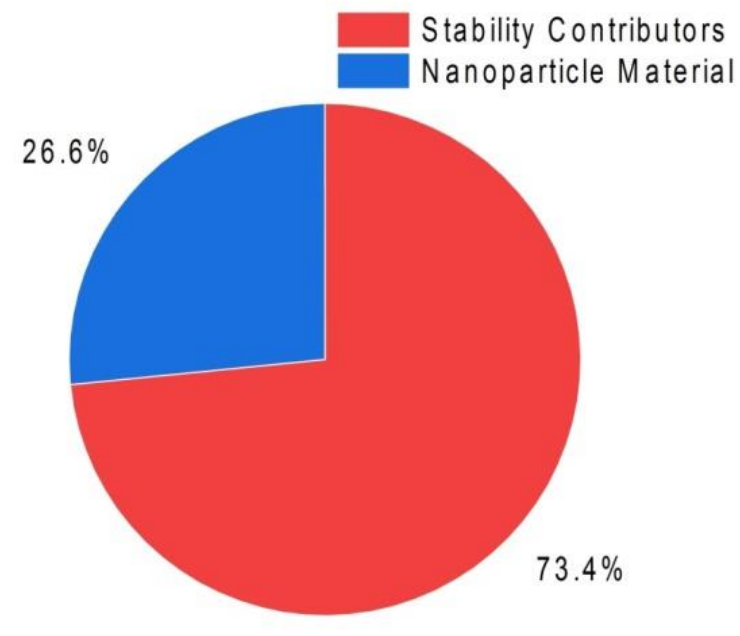

Figure 10. Comparison of the impact of stability contributors and nanoparticle material on thermal conductivity

Similar behavior was also reported by Chen et al [36] where the authors investigated the effect of cationic Gemini surfactant on the properties of multi-walled carbon nanotube nanofluid. They found that less stable nanofluids have lower thermal conductivity. The less stable nanofluid with high thermal conductivity particles can provide inferior thermal conductivity than stable nanofluid with low thermal conductivity particles. The low thermal conductivity in less stable nanofluids is the result of the low Brownian motion of the nanoparticles compared to stable nanofluids, in which nanoparticles have high 
surface charge and a high movement of particles. As the Brownian motion of nanoparticles plays a key role in deciding thermal behavior, the thermal conductivity decreases with Brownian $[37,38]$. Hence while comparing different nanofluids; the stability of the nanofluid also be given prominence rather along with thermal conductivity of the nanoparticles.

\subsection{Mathematical approach on thermal conductivity of nanofluids}

The Brownian motion theory for thermal conductivity enhancement is a predominantly explored mechanism that explains the high change in thermal conductivity with the change in temperature [39, 40]. In this section, the Brownian motion mechanism and its relationship with process parameters are explored. Koo et al. [41] have developed a mathematical model for thermal conductivity which considers the effective thermal conductivity of nanofluids to be composed of a static part and the part due to Brownian motion.

$$
k_{\text {eff }}=k_{\text {static }}+k_{\text {Brownian }}
$$

But, it is suggested that at low concentration $(<1 \%)$ the $k_{\text {static }}$ is negligible and $k_{\text {Brownian }}$ plays a dominant role in the effective thermal conductivity. Hence it can be assumed that in this study $k_{\text {Brownian }}$ is the primary mechanism that affects the effective thermal conductivity and $k_{\text {static }}$ can be neglected from Eq. (6). The $k_{\text {Brownian }}$ is given as [41];

$$
k_{\text {Brownian }}=\sqrt{\frac{18}{\pi}} P * \rho_{d} * \alpha_{d} * C_{v} \sqrt{\frac{k_{B} T}{\rho_{d} D} * \frac{l}{D}}
$$

Where, $K=$ Boltzmann Constant, $P=$ probability of particle to travel in any direction, $T=$ Temperature of the sample, $\rho_{\mathrm{d}}=$ Particle density, $\alpha_{\mathrm{d}}=$ Particle concentration, $D=$ particle diameter and $l=$ average distance of particle travel.

Hence,

$$
k_{\text {Brownian }}=f\left(P, C_{v}, \rho_{d}, \alpha_{d}, T, D, l\right)
$$

As all the measurements of the thermal conductivity are taken at the $25^{\circ} \mathrm{C}$, so there are no variations in the thermal conductivity with temperature. Similarly, $\rho$ and $\alpha$ of all the nanofluid samples are the same. In Eq. (7), the factors $P, D$, and $l$ are the factors that are highly dependent on the preparation parameters (surfactant material, weight, and sonication time). The surfactant material and weight affect the surface charge on the nanoparticle which enhances interparticle potential. This enhances the particle movement and increases the probability of the particle to travel along any direction $(P)$. Similarly, the particle diameter $(D)$ is also highly dependent on the sonication time, surfactant material, and weight.

The stability of nanofluid is characterized by particle size and high particle mobility due to a surface charge which can be observed through turbidity in this study. The preparation parameters affect the size and mobility of particles, the low particle size and high particle mobility increase the Brownian motion and hence Brownian thermal conductivity of nanofluid increases. This enhancement in the thermal conductivity of the nanofluids with lower particle size is observed by many researchers with $\mathrm{Al}_{2} \mathrm{O}_{3}$ [42], $\mathrm{CuO}$ [43], $\mathrm{TiO}_{2}$ [44], and $\mathrm{ZnO}$ [45] nanoparticles. This interrelation between preparation parameters, stability, and thermal conductivity is schematically represented in Fig. 11. It can be concluded from Equation (8) that for the same material nanofluids the thermal conductivity is strongly dependent on particle size and high mobility of the particles and hence also on the stability of the nanofluid. Along with the Brownian motion mechanism of thermal conductivity, in the interfacial liquid layer mechanism also, the small particle sizes are desirable for the higher thermal conductivity enhancement as it is hypothesized that liquid layer thickness is dependent on the particle diameter [46]. Hence the change in effective thermal conductivity of the nanofluids contributed by different mechanisms and their relation to the preparation parameters are further needed to be explored. 


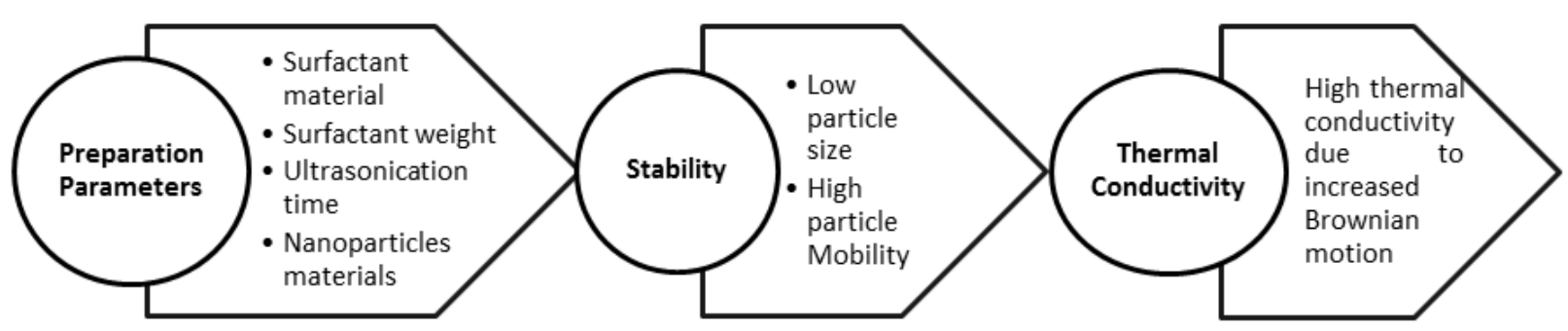

Figure 11. Interrelation in between preparation parameters, stability, and thermal conductivity

\section{CONCLUSIONS}

In this paper, Taguchi analysis of the thermal conductivity of nanofluids is conducted using surfactant material, surfactant weight, ultrasonication time, and nanoparticle materials as process parameters. This approach explores the role of preparation parameters and stability in the thermal conductivity of nanofluids. It is observed that $\mathrm{CuO}$ nanoparticle with $\mathrm{CTAB}$ surfactant and preparation parameters of $0.5 \%$ surfactant weight and 15 minutes ultrasonication has the best thermal conductivity. Taguchi analysis shows that the $\mathrm{CuO}$-water nanofluid delivers the highest thermal conductivity compare to $\mathrm{Fe}_{3} \mathrm{O}_{4}$-water and $\mathrm{CuO}+\mathrm{Fe}_{3} \mathrm{O}_{4}$-water nanofluids. Nanofluid samples with $\mathrm{CTAB}$ and SDS surfactant show higher turbidity than the nanofluids with CA surfactant. It is also observed that the SNR for CA is considerably lower than CTAB and SDS. The stable nanofluids with CTAB and SDS surfactant provide higher thermal conductivity than the unstable nanofluids with CA surfactants.

The results of ANOVA show that the nanoparticle material is not the sole contributor to the thermal conductivity, but surfactant material, quantity, and ultrasonication time collectively play an overwhelmingly dominant role. This work also highlights that though it is statistically observed that the surfactant material, quantity, and ultrasonication time play a dominant role in the thermal conductivity of nanofluids, they do not directly influence the thermal conductivity. Their effect is manifested as an improvement in the stability which in turn results in the overall enhancement of the thermal conductivity of the nanofluid.

\section{REFERENCES}

[1] Kleinstreuer C, Feng Y. Experimental and theoretical studies of nanofluid thermal conductivity enhancement: a review. Nanoscale Res Lett 6. 2011;229.

[2] Sureshkumar R, Tharves Mohideen S, Nethaji N. Heat transfer characteristics of nanofluids in heat pipes: A review. Renewable and Sustainable Energy Reviews. 2013;20:397-410.

[3] Kulkarni D, Das D, Vajjha R. Application of nanofluids in heating buildings and reducing pollution. Applied Energy. 2009;86:12:2566-2573.

[4] Senthilraja S, Karthikeyan M, Gangadevi R. Nanofluid Applications in Future Automobiles: Comprehensive Review of Existing Data. Nano-Micro Lett. 2, 306-310.

[5] Sidik N, Yazid M, Mamat R. A review on the application of nanofluids in vehicle engine cooling system. International Communications in Heat and Mass Transfer. 2015;68:85-90.

[6] Sajid M, Ali H, Recent advances in application of nanofluids in heat transfer devices: A critical review. Renewable and Sustainable Energy Reviews. 2019;103:556-592.

[7] Martin K, Sözen A, Çiftçi E, Ali H. An experimental investigation on aqueous $\mathrm{Fe}-\mathrm{CuO}$ hybrid nanofluid usage in a plain heat pipe. International Journal of Thermophysics. 2020;41:135:1-21. DOI:10.1007/s10765020-02716-6.

[8] Aydın D, Çiftçi E, Gürü M, Sözen A. The impacts of nanoparticle concentration and surfactant type on thermal performance of a thermosyphon heat pipe working with bauxite nanofluid, Energy Sources, Part A: Recovery, Utilization, and Environmental Effects, 2020;1-24. DOI: 10.1080/15567036.2020.1800141. 
[9] Sözen A, Khanları A, Ciftci E, Heat transfer enhancement of plate heat exchanger utilizing kaolin-including working fluid, Proc IMechE Part A: J Power and Energy, 2019;1-9. DOI: 10.1177/0957650919832445.

[10] Gürbüz E, Variyenli H, Sözen A, Khanlari A, Ökten M. Experimental and numerical analysis on using CuOA12O3/water hybrid nanofluid in a U-type tubular heat exchanger. International Journal of Numerical Methods for Heat \& Fluid Flow. 2020;0961-5539. DOI 10.1108/HFF-04-2020-0195.

[11] Eapen J, Rusconi R, Piazza R, Yip S. The classical nature of thermal conduction in nanofluids. Journal of Heat Transfer, 2010;132(10):102402.

[12] Sarviya R, Fuskele V. Review on Thermal Conductivity of Nanofluids, Materials Today: Proceedings. 2017;4:4022-31.

[13] Kotia A, Borkakoti S, Deval P, Ghosh S, Review of interfacial layer's effect on thermal conductivity in nanofluid, Heat Mass Transfer, 2017;53:2199-2209.

[14] Henderson J., Frank S. On the interface between a fluid and a planar wall, Molecular Physics: An International Journal at the Interface Between Chemistry and Physics. 1984;51:4:991-1010.

[15] Rizvi I, Jain A, Ghosh S, Mukherjee P.S. Mathematical modelling of thermal conductivity for nanofluid considering interfacial nano-layer. Heat Mass Transfer. 2013;49:595-600.

[16] Kouloulias K, Sergis A, Hardalupas Y. Sedimentation in nanofluids during a natural convection experiment. International Journal of Heat and Mass Transfer. 2016;101:1193-1203.

[17] Slamet, Redjeki A. S. Interaction between surfactant and titania in a detergent nanofluid system. 2017. doi:10.1063/1.5011920.

[18] Choudhary R, Khurana D, Kumar A, Subudhi S. Stability analysis of Al2O3/water nanofluids. Journal of Experimental Nanoscience. 2017;12-1:140-51.

[19] Xuan Y, Li Q, Tie P. The effect of surfactants on heat transfer feature of nanofluids. Experimental Thermal and Fluid Science. 2013;46:259-262.

[20] Mahbubul I, Saidur R, Amalina M, Elcioglu E, Okutucu-Ozyurt T. Effective ultrasonication process for better colloidal dispersion of nanofluid. Ultrasonics Sonochemistry. 2015;26:361-369.

[21] Asadi A, Alarifi I, Ali V, Nguyen H. An experimental investigation on the effects of ultrasonication time on stability and thermal conductivity of MWCNT-water nanofluid: Finding the optimum ultrasonication time. Ultrasonics - Sonochemistry. 2019;58:104639.

[22] Mugica I, Poncet S, A critical review of the most popular mathematical models for nanofluid thermal conductivity, Journal of Nanoparticle Research, 2020;22:113, https://doi.org/10.1007/s11051-020-4776-y

[23] Elsayed MM, Cevc G. Turbidity spectroscopy for characterization of submicroscopic drug carriers, such as nanoparticles and lipid vesicles: size determination. Pharm Res. 2011;28:2204-2222. doi:10.1007/s11095011-0448-z.

[24] Dharmalingam,Sivagnanaprabhu K, Chinnasamy C, Senthilkumar B. Optimization studies on the performance characteristics of solar flat - plate collector using Taguchi Method, Middle-East Journal of Scientific Research, 2015;23(5):861-868.

[25] Elcioglua E, Yazicioglu A, Turgut A, Anagun A. Experimental study and Taguchi Analysis on alumina-water nanofluid viscosity, Applied Thermal Engineering, 2018;128: 973-981.

[26] Horng-Wen W, Zhan-Yi W. Using Taguchi method on combustion performance of a diesel engine with diesel/biodiesel blend and port-inducting $\mathrm{H}_{2}$, Applied Energy, 2013:104:362-370.

[27] Taguchi G. Introduction to quality engineering. Whiter Plains, New York: Kraus International Publications. 1986.

[28] Allen Zennifer M, Manikandan S, Suganthi K S, Vinodhan V, Rajan K S. Development of CuO-ethylene glycol nanofluids for efficient energy management: Assessment of potential for energy recovery, Energy Conversion and Management, 2015:105;685-696.

[29] Zhai Y, Li L, Wang J, Li Z. Evaluation of surfactant on stability and thermal performance of $\mathrm{Al}_{2} \mathrm{O}_{3}$-ethylene glycol (EG) nanofluids. Powder Technology, 2019;343:215-224.

[30] Savithiri S, Pattamatta A, Das S K. Scaling analysis for the investigation of slip mechanisms in nanofluids. Nanoscale Res Lett, 2011;6:471. 10.1186/1556-276X-6-471.

[31] Lemmon E, Huber M, McLinden M. Reference Fluid Thermodynamic and Transport Properties (REFPROP), Ver. 9.0, National Institute of Standards and Technology.

[32] Holman J. P. Experimental Methods for Engineers, seventh ed. New York: McGraw-Hill. 2001.

[33] Gopalsamy B M, Mondal B, Ghosh S. Taguchi method and ANOVA: An Approach for process parameters optimisation of Hard Machining while machining hardened steel, Journal of scientific and industrial research, 2009;68:686-695.

[34] Das P K. A review based on the effect and mechanism of thermal conductivity ofnormal nanofluids and hybrid nanofluids, Journal of Molecular Liquids. 2017;240:420-446.

[35] X.J. Wang, D.S. Zhu, S. Yang. Investigation of $\mathrm{pH}$ and SDBS on enhancement of thermal conductivity in nanofluids, Chemical Physics Letters, 2009;470:107-111. 
[36] Chen L, Xie H. Properties of carbon nanotube nanofluids stabilized by cationic gemini surfactant. Thermochimica Acta. 2010;506:62-66.

[37] Jang S, Choi S. Role of Brownian motion in the enhanced thermal conductivity of nanofluids. Applied Physics Letters. 2004;84:4316. doi: 10.1063/1.1756684

[38] Mukherjee S, Mishra P C, Chaudhuri P. Enhancing Thermo-Economic Performance of TiO2-Water Nanofluids: An Experimental Investigation. JOM,2020. https://doi.org/10.1007/s11837-020-04336-9

[39] Michaelides EE, Nanofluidics. Springer, Switzerland, 2014.

[40] Das SK, Putra N, Thiesen P, Roetzel W. Temperature dependence of thermal conductivity enhancement for nanofluids. Journal of Heat Transfer, 2003;125(4):567-574.

[41] Koo J, Kleinstreuer C. A new thermal conductivity model for nanofluids. Journal of Nanoparticle Research. 2004;6:577-588.

[42] Teng T P, Hung Y H, Teng T C, Moa H E, Hsu H G, The effect of alumina/water nanofluid particle size on thermal conductivity, Appl. Therm. Eng., 2010;2213-2218.

[43] Mintsa H A, Roy G, Nguyen C T, Doucet D. New temperature dependent thermal conductivity data for waterbased nanofluids, Int. J. Therm. Sci. 2009;48;363-371.

[44] He Y, Jin Y, Chen H, Ding Y, Cang D, Lu H. Heat transfer and flow behaviour of aqueous suspensions of TiO2 nanoparticles (nanofluids) flowing upward through a vertical pipe, Int. J. Heat Mass Transf. 2007;50;2272-2281.

[45] Kim S H, Choi S R, Kim D. Thermal conductivity of metal oxide nanofluids: particle size dependence and effect of laser irradiation, J. Heat Transf. 2007;129;298-307.

[46]Zhi L, Hai-Lung T. Thermal conductivity of interfacial layers in nanofluids, Physical Review E, 2011;83:041602 